\title{
Best Practices for Health Informatician Involvement in Interprofessional Health Care
} Teams

\author{
Richard J. Holden ${ }^{1,2}$ Samar Binkheder ${ }^{1,3}$ Jay Patel ${ }^{1}$ \\ ${ }^{1}$ Department of BioHealth Informatics, Indiana University School of \\ Informatics and Computing-IUPUI, Indianapolis, Indiana, \\ United States \\ 2 Indiana University Center for Aging Research and Center for \\ Biomedical Informatics, Regenstrief Institute, Inc., Indianapolis, \\ Indiana, United States \\ 3 Medical Informatics Unit, College of Medicine, King Saud University, \\ Riyadh, Saudi Arabia
}

Appl Clin Inform 2018;9:141-148.

Academic and nonacademic health informatics (HI) professionals (informaticians) serve on interprofessional health care teams with other professionals, such as physicians, nurses, pharmacists, dentists, and nutritionists. ${ }^{1}$ Presently, we argue for investing greater attention to the role health informaticians play on interprofessional teams and the best practices to support this role.

\section{The Role of Health Informaticians on Interprofessional Health Care Teams}

In interprofessional health care teams, individuals with distinct professional training supply unique expertise and work together to solve health care problems. ${ }^{2,3}$ When these teams span different branches of knowledge or subspecialties, they are also considered interdisciplinary. ${ }^{2,4}$ Interprofessional teams in health care are effective because they draw on diverse expertise to address complex problems in holistic ways. ${ }^{5,6}$ Interprofessional teams operate in health care facilities, academic institutions, and community or public health settings. ${ }^{7}$ In clinical settings, interprofessional teams provide less fragmented, ${ }^{8,9}$ higher quality, ${ }^{9,10}$ safer, ${ }^{11}$ and more effective ${ }^{12-14}$ care. Interprofessional teams are recommended by the World Health Organization ${ }^{15,16}$ and the National Academy of Medicine. ${ }^{17}$ Further, educational institutions and accreditors, ${ }^{18}$ including the Accreditation Committee for Graduate Medical Education (ACGME), ${ }^{19}$ embrace interprofessional education (IPE), to prepare health care professionals "for the world of intercollaborative practice." ${ }^{7}$ In parallel, the National Institutes of Health and others urge interdisciplinary "team science" in biomedical research. ${ }^{20}$

Are health informaticians considered members of interprofessional teams? Our informal review of major textbooks, ${ }^{21,22}$ reports, and articles ${ }^{1,23-25}$ found no mention of health informaticians as members of interprofessional health care teams. A published 2013 review described the make-up of interprofessional teams in 17 articles $^{26}$; informaticians were not included in any (see - Supplementary Material, available in the online version). Furthermore, including HI students in IPE initiatives appears to be an exception, not the rule. ${ }^{27,28}$ When $\mathrm{HI}$ is mentioned in the literature on interprofessional health care, it is as a set of tools that "has the capacity to support the work of health care teams" ${ }^{29}$ and improve IPE. ${ }^{30}$

We argue that health informaticians have a professional role on teams, apart from providing direct care. ${ }^{a}$ This role should be better defined and communicated to other professions. When a problem involves data or information, informaticians add value by applying competencies in "management and use of biomedical information." ${ }^{31}$ This is evident in realms such as evidencebased health care delivery, ${ }^{32}$ precision medicine, ${ }^{33}$ population health management, ${ }^{34}$ public health surveillance, ${ }^{35}$ and

\footnotetext{
a We note some informaticians do provide direct care as trained and licensed physicians, nurses, dentists, pharmacists, therapists, social workers, midwives, etc. Further, as the scope of health professionalism changes, some informaticians who practice in public health, care coordination, or wellness coaching may be thought to provide care. However, our main point is a team member in the domains of health and healthcare can impart value without providing direct care.
}

received

November 15, 2017

accepted after revision

January 1, 2018
Copyright $\odot 2018$ Schattauer

DOI https://doi.org/

$10.1055 / \mathrm{s}-0038-1626724$.

ISSN 1869-0327. 
learning health systems. ${ }^{36,37}$ Health informaticians are qualified to handle both electronic health records and larger health care data sets to answer questions, support care delivery, improve quality and efficiency, and reduce costs. ${ }^{38}$ Examples include building or identifying databases or data sets, mining structured/unstructured data, applying computational procedures, interpreting data/results, and sharing data. In many other cases, health informaticians add value by applying competencies in "design, development, adoption, and application of information technology (IT)-based innovations." ${ }^{39}$ Informaticians can develop methodologies and technologies to advance team research, design tools and networks to facilitate interprofessional collaboration and communication, and develop standards and terminologies to support system interoperability. ${ }^{40}$

We argue health informaticians are useful members of interprofessional teams in all stages of problem-solvingproblem assessment, solution development, implementation, and evaluation, as illustrated in -Table 1. In part, this is because HI education is interdisciplinary, covering health, social, and technical domains, such as biomedical sciences, computer and data sciences, human factors and decisionmaking, and social and behavioral science. ${ }^{41,42}$ Furthermore, properly trained health informaticians gain interprofessional collaboration and leadership competencies, including leading and managing change. ${ }^{41-43}$ This is evidenced by the inclusion of team competencies in $\mathrm{HI}$ accreditation and board certification requirements. ${ }^{41,44}$ The American Medical Informatics Association (AMIA) Accreditation Committee, for instance, lists interprofessional collaborative practice (F9) and leadership (F10) among its 10 foundational domains of $\mathrm{HI}^{41}$ Health informaticians can thus play the role of visionary, innovator, bridge, facilitator, and evangelist on interprofessional teams. ${ }^{8}$
In our experience, one of the most important though undervalued roles informaticians play on teams is the figurative multilinguistic (symphonic) conductor. This entails sufficiently learning each team member's discipline- or profession-specific values, norms, practices, vocabularies, theories, and methods to coordinate and translate between dissimilar members.

A question facing $\mathrm{HI}$ and other disciplines is whether teams must include a formally trained HI professional, rather than someone possessing informatics competencies. The answer depends on access to health informaticians, availability of $\mathrm{HI}$ training available to noninformaticians, and the ability of the team to cover the breadth of relevant HI competencies described above. For example, a team should not replace a health informatician with a software engineer unfamiliar with the health care domain.

\section{Best Practices for Health Informatician Involvement in Interprofessional Teams}

Having argued for the need to recognize and define the role of health informaticians on interprofessional teams, we now turn to best practices for optimizing this role (-Table 2). Our seven suggested best practices were compiled from the literature and our experience with interprofessional collaboration and education. We also illustrate how each best practice was applied in a project addressing the opioid crisis in a university-based IPE course involving students and faculty coaches representing HI, nursing, medicine, art and design, and engineering (see - Table 3). The best practices and recommendations apply to HI students, certified clinical informaticians, HI researchers, and other HI professionals.

Table 1 Example medication safety project with and without health informatician involvement

\begin{tabular}{|c|c|c|}
\hline Project phase & Health informatician involved & No involvement of health informatician \\
\hline $\begin{array}{l}\text { Situation } \\
\text { assessment }\end{array}$ & $\begin{array}{l}\text { - Data obtained from health system used to assess } \\
\text { the situation } \\
\text { - Simulation and predictive models built to } \\
\text { identify most prevalent unsafe medications } \\
\text { - Interviews, surveys, and observations performed } \\
\text { to learn patient and clinician information needs } \\
\text { and decision-making process }\end{array}$ & $\begin{array}{l}\text { - Key data missing from problem assessment } \\
\text { - Could not prioritize or focus on specific } \\
\text { medications } \\
\text { - Clinical priorities emphasized, patient informa- } \\
\text { tion needs ignored } \\
\text { - Incorrect assumptions made about how } \\
\text { individuals make decisions }\end{array}$ \\
\hline $\begin{array}{l}\text { Solution } \\
\text { development }\end{array}$ & $\begin{array}{l}\text { - Solution includes patient- and clinician-facing } \\
\text { software changes } \\
\text { - Solution applies rules to target most prevalent } \\
\text { unsafe medications } \\
\text { - Decision support solution created using } \\
\text { user-centered design and iterative testing } \\
\text { - Solution is interoperable }\end{array}$ & $\begin{array}{l}\text { - Software not part of the solution } \\
\text { - Targeting too many medications leads to } \\
\text { untenable solution } \\
\text { - Solution does not conform with usability prin- } \\
\text { ciples, is not usable or acceptable to end-users } \\
\text { - Solution does not work with existing software } \\
\text { and technical infrastructure }\end{array}$ \\
\hline $\begin{array}{l}\text { Implementation } \\
\text { and evaluation }\end{array}$ & $\begin{array}{l}\text { - Intervention deployed and tracked in health } \\
\text { system's EHR system } \\
\text { - Medication data mined from EHR, compared } \\
\text { pre-post intervention at individual and group } \\
\text { levels } \\
\text { - Informatician presents technical and business } \\
\text { plans to leadership } \\
\text { - Key organizational and political constraints } \\
\text { successfully navigated }\end{array}$ & $\begin{array}{l}\text { - Intervention cannot be deployed to all EHR } \\
\text { system users } \\
\text { - Data not available to perform objective pre-post } \\
\text { evaluation } \\
\text { - Contradictory technical and business plans } \\
\text { written by different individuals } \\
\text { - Failure to consider social (organizational/political) } \\
\text { aspects results in unanticipated resistance }\end{array}$ \\
\hline
\end{tabular}

Abbreviation: EHR, electronic health records. 
Table 2 Best practices for health informatician involvement in interprofessional teams

\section{BP Recommendations}

BP1. Adopt the characteristics of effective teams

- Clear vision and goals 43,45

- Mutual respect and shared values ${ }^{7,41}$

- Supportive climate 45

- Diverse skill mix across team members 45

- Clear roles and boundaries for each member ${ }^{43,46,47}$

- Continuous learning and training ${ }^{45,48}$

- Formal process for conflict management ${ }^{49,50}$

- Practice performance monitoring and feedback, back-up behavior, and adaptation ${ }^{51,52}$

BP2. Practice leadership and followership

- Clearly identify a leader to direct, support, and supervise the team ${ }^{45}$

- Leaders should be appointed or quickly emerge ${ }^{53}$

- The leader should be credible, honest, competent, able to inspire, and able to focus the team on the vision ${ }^{41}$

- The team must understand the importance and roles of leadership in coordinating the team's contributions ${ }^{54}$ and achieving its goals ${ }^{41}$

- Team members should practice good followership ${ }^{41}$

- Use leadership tools, for example, for planning and performance review ${ }^{50}$

- A team leader establishes a shared belief in the value of collaboration ${ }^{55}$

- Leaders focus, coordinate, and create shared mental models for the team ${ }^{53}$

BP3. Clearly communicate with the aid of tools

- Communication success begins with shared understanding, mutual respect, and agreed-upon ground rules ${ }^{7,41}$

- Use informatics knowledge to establish effective communication technology and tools 55

- Use communication tools ${ }^{50}$ such as SBAR, ${ }^{56}$ Call-Out, Check-Back, and Hand-off

- Err on the side of over- rather than under-communication, for example, making sure to include all recipients on e-mails

- Create artifacts to summarize and organize information for shared situation awareness and future reference (e.g., meeting notes, project charters, Gantt charts)

BP4. Design team meetings for effectiveness and efficiency

- Good meetings are a result of careful planning, attention to participants' needs, and follow-through ${ }^{57}$

- Use early meetings to establish the team's purpose, goals, members' roles and responsibilities, meeting and reporting plan, deliverables, and timetable ${ }^{43}$

- Adopt a team meeting framework and recommendations (see Schleyer et al ${ }^{43}$ for detail)

- If possible, organize in-person meetings ${ }^{55}$

BP5. Articulate your skills with respect to health informatics

- Explain to teammates the breadth of HI

- Explain to teammates the specialization(s) within $\mathrm{HI}$ represented by $\mathrm{HI}$ team members

- Act politely and be forgiving when a team member has incorrect assumptions or perceptions of your skills: offer gentle corrections with the goal of educating and enhancing your effectiveness and efficiency in the team

- Inform team members of data needs early in the project lifecycle, to facilitate future access to health care data $a^{58}$

- Ensure team members' understanding and use of proper terminology and techniques related to health data ${ }^{58}$

BP6. Develop skills and knowledge in interprofessional teamwork and domains

- Understand roles and values of all team members $7,41,45$

- Interact with and learn from other professions, being attentive to their languages and practices ${ }^{59}$

- Seek out interprofessional collaboration and cross-training opportunities before graduation 60

- Establish interprofessional collaborative practice culture and team (not individual) reward systems 30

- Work to improve team skills such as self-assessment of strengths and weakness, listening, and managing shared goals, in addition to gaining domain knowledge ${ }^{62}$

BP7. Ensure health informatics education supports interprofessional collaboration

- Align HI professional education with above best practices 47

- Offer opportunities for hands-on health care problem solving in interprofessional teams, using interdisciplinary informatics approaches, with faculty feedback and support ${ }^{48,50}$

- Faculty should provide interprofessional opportunities, feedback, and support ${ }^{48,50}$ as well as themselves come from different disciplines ${ }^{61}$

- Use simulation-based training with real-world scenarios to train $\mathrm{HI}$ students for work environment ${ }^{48}$

- Partner with campus IPE programs

Abbreviations: BP, best practice; HI, health informatics; IPE, interprofessional education. 
Table 3 Illustration of how the seven recommended best practices were applied in a university-based interprofessional education course involving students and faculty coaches representing health informatics, nursing, medicine, art and design, and engineering

- BP1. Adopt the characteristics of effective teams

- Faculty divided teams to promote diverse mix of professions and skills

- Team leader brought team to early consensus on project scope

- BP2. Practice leadership and followership

- Leader emerged in the first week, with team consensus and faculty coach approval

- Team leader created the plan, assigned roles and tasks, and held team members accountable

- Leader communicated with outside stakeholders on behalf of the team

- BP3. Clearly communicate with the aid of tools

- Teams had regular scheduled meetings face-to-face or using online conferencing system; face-to-face meetings were most effective but more difficult to achieve

- Teams used online cloud-based storage, for viewing progress and team documents

- BP4. Design team meetings for effectiveness and efficiency

- Team members agreed to and held each other accountable for regular, in-person meetings of the entire team

- Team used meetings for updates on progress and updating the plan

- Team used resources such as white boards and note-taking to support meetings

- BP5. Articulate your skills with respect to health informatics

- HI team members corrected team members' assumptions when asked to play a role outside their HI specialty

- HI team members provided team mates with an explanation of $\mathrm{HI}$ breadth and their specific skill/knowledge areas

- HI team members tackled barriers to acquiring data from stakeholders to assess the situation or test an informatics solution

- BP6. Develop skills and knowledge in interprofessional teamwork and domains

- HI team members spent extra time learning about the practices and assumptions of teammates' professions

- HI team members had to learn professional and clinical jargon

- HI team members had to learn the realities of health care delivery, which clinical teammates had gained through hands-on experience

- BP7. Ensure health informatics education supports interprofessional collaboration

- The IPE course allowed HI students to work with students representing other professions

- HI students received coaching and education in interprofessionalism, teamwork, and problem solving

- Diverse faculty, guest judges, and community stakeholders representing multiple professions and disciplines provided a guided learning experience

Abbreviation: BP, best practice.

Note: See Supplementary Material for details about the interprofessional education course.

\section{Best Practice \#1-Adopt the Characteristics of Effective Teams}

There are multiple evidence-based accounts of the characteristics of effective teams and how to achieve them, ${ }^{48,63,64}$ listed in -Table 2. Successful teams set goals, monitor each others' performance, balance workload between team members, and adapt to deviations. ${ }^{52,65}$ Health informaticians can make teams more effective by increasing the team's skill mix and setting clear expectations for their roles and duties relative to their skills. ${ }^{43}$ For instance, a health informatician could take the responsibility for data analysis or management tasks.

\section{Best Practice Implication \#2-Practice Leadership and Followership}

According to the AMIA's HI core competencies, leadership refers to the "process for which the output is vision, guidance, and direction." 41 Leadership facilitates action, in addition to supporting team psychosocial needs, such as morale, motivation, and confidence. ${ }^{51}$ In interprofessional teams, leaders must instill the belief that collaboration adds value. ${ }^{55}$ Likewise, a health informatician leader must convince the team of the value and applicability of HI. Leaders often hold others accountable and represent the team to outside stakeholders, meaning HI professionals must learn to interact with decision-makers who are noninformaticians (e.g., avoiding or explaining informatics jargon). HI competencies also dictate practicing followership and supporting leaders from other professions. ${ }^{41}$ Although traditionally there is one leader, there is theoretical and practical guidance for shared or distributed leadership approaches. $^{66,67}$ Shared leadership may be relevant when the health informatician is in charge of methodological aspects but a clinical professional provides clinical leadership.

\section{Best Practice \#3-Clearly Communicate with the Aid of Tools}

HI professionals should be skilled in applying the "principles of interprofessional communication in a responsive and responsible manner that supports a team approach." 41 Good communication starts with a common language and shared understanding, which means health informaticians need to learn and respect their teammates' language and professional identities, ${ }^{55}$ while carefully selecting which informatics terms and concepts to introduce. Early on, communication can be aided by creating artifacts, such as team charters or social contracts, which explicitly establish expectations for communication, including frequency, method, and what constitutes timely and 
respectful responses. As team projects move forward, other tools and artifacts become more useful, for example, handoff procedures, stable communication channels (e.g., mailing lists, chat rooms), and storage space for team documents (e.g., meeting minutes). A health informatician may need to advise on appropriate communication technologies, especially when the communication concerns sensitive patient data, large data sets, or the use of clinical information systems (e.g., internal messaging).

\section{Best Practice \#4-Design Team Meetings for Effectiveness and Efficiency}

Despite their bad reputation, team meetings can yield irreplaceable benefits with careful planning, attention to participants' needs, and follow-through. ${ }^{57}$ In the beginning, welldesigned meetings help establish the team's purpose, membership, structure, process, and resources. They are also an opportunity to learn the value of each team member, beyond their professional titles. This is especially important when the team has vague or incorrect knowledge of the HI profession. During the course of project work, meetings provide a forum for reporting progress, planning and replanning, resolving conflict, team brainstorming and feedback, and relationship building. Schleyer et $\mathrm{al}^{43}$ provide a framework and specific guidance for effective and efficient team meetings for $\mathrm{HI}$ professionals, covering topics such as in-person versus electronic meetings, meeting space and technology, the use of agendas and meeting minutes, and meeting procedures.

\section{Best Practice \#5-Articulate Your Skills with Respect to Health Informatics}

$\mathrm{HI}$ is itself interdisciplinary, producing professionals with differing subspecializations and roles. ${ }^{68}$ Members of interprofessional health care teams are already dissimilar, ${ }^{46,47}$ but health informaticians have an added burden of representing a profession lesser known within the health care community. Specifically, HI has wide-ranging meanings, ${ }^{69}$ so team members may have a restricted understanding of their health informatician teammates, leading to misaligned expectations. For example, an informatician may be viewed as a "data person" or "technology person"; these are true of some, but not all. A team member might also have an erroneous understanding of HI, for example, believing informaticians merely provide "programming" or "tech support."b The breadth of HI has two implications for interprofessional teamwork. First, an $\mathrm{HI}$ professional must be ready to articulate the full extent of $\mathrm{HI}$, for the education of teammates, and the good of the profession. Second, the HI professional must define their personal training, experience, and specialization(s) on the continuum of $\mathrm{HI}$ competencies. (Similar considerations apply to working on intraprofessional HI teams.)

\footnotetext{
b We admit to a mix of amusement and frustration when looked upon as experts at setting up teleconferencing or navigating file storage systems; this is especially so when we are indeed the best on the team at these technical tasks.
}

A corollary best practice is once the team understands the HI team member's skills, there is an additional challenge of assigning and supporting an appropriate role for him or her. This is facilitated by, for example, the ubiquity of information and IT in health care. However, in our experience, many $\mathrm{HI}$ contributions require access to data, and data may not be readily accessible to or understood by the interprofessional team. This may be especially common in limited-resource or educational settings, prohibiting the HI team member from exercising their competencies in data analytics, modeling, and mining. ${ }^{41,70}$ Health informaticians are therefore advised to secure as early as possible the resources they need to play their role on the team.

\section{Best Practice \#6-Develop Skills and Knowledge in Interprofessional Teamwork and Domains}

At the same time, HI professionals need to understand and respect other professions, facilitated by IPE and other interprofessional interactions. ${ }^{41,71}$ Another avenue of learning outside the HI profession is cross-training, which can range from experiential learning in "real-world" contexts to reading about outside disciplines. ${ }^{33,72}$ This is especially important for those health informaticians who have limited clinical exposure or prior training, and need to work with professionals who have accumulated clinical experience, vocabularies, and assumptions over such a long time that it is implicit (i.e., learned intuition). Health informaticians must therefore learn not only HI skills, but also teamwork and at least the basics of other professions. ${ }^{59}$ Similarly, they must find ways to become knowledgeable in their application domains (e.g., pediatrics, decision-making, artificial intelligence), as must their teammates. These recommendations can be addressed in part by involving HI students in IPE offerings.

Best Practice \#7-Ensure Health Informatics Education Supports Interprofessional Collaboration

Ensuring HI students are trained in interprofessional collaboration is a natural extension of the preceding best practices and aligned with $\mathrm{HI}$ core competencies and foundations. ${ }^{41,73}$ HI education should engage students to collaborate with other professionals, solve "real-world" health care challenges, and apply interdisciplinary methodologies. ${ }^{74} \mathrm{HI}$ programs should strive for both integration with other campus IPE initiatives and creation of living laboratories for hands-on application of HI competencies. ${ }^{33}$

\section{Conclusion}

The evolution of health care systems encourages-even requires-involving $\mathrm{HI}$ expertise in interprofessional health care teams and real-world problem solving. Our present objective is to heighten interest in defining and improving health informatician involvement in interprofessional teams. We encourage others in the discipline to join the conversation, including scientifically validating and applying the above best practices and contributing their own. 


\section{Multiple Choice Questions}

1. Which of the following statements is the most accurate? a. Health informaticists add value to interprofessional health care teams, and are always considered members of these teams

b. Health informaticists add value to interprofessional health care teams, but are rarely considered members of these teams

c. Health informaticists do not add value to interprofessional health care teams, and are rarely considered members of these teams

d. Health informaticists do not add value to interprofessional health care teams, unless they are the team leader

Correct Answer: The correct answer is option b, health informaticists add value to interprofessional health care teams, but are rarely considered members of these teams.

2. To be effective as an interprofessional team member, what should a health informatics professional do?

a. Avoid learning the terminologies used by noninformatician team members.

b. Refuse to offer advice on which communication tools to use because it is beneath them.

c. Privately select their own goals and work on only these.

d. Take courses in which they practice working with other professions to solve real-world problems.

Correct Answer: The correct answer is option d, take courses in which they practice working with other professions to solve real-world problems.

\section{Authors' Contributions}

All authors (R.J.H., S.B., J.P., S.H.P.V.) contributed to conception, design, drafting, and critical revision.

Protection of Human and Animal Subjects

No human subjects were involved.

\section{Conflict of Interest}

None.

\section{Acknowledgments}

We thank the participants in the Indiana University interprofessional education course, particularly the students, faculty, guest judges, and community stakeholders. We thank Dr. Julie Poore and Dr. Josette Jones for their review of the manuscript and the journal editor and reviewers for their comments. We thank Dr. Malaz Boustani, who originated the concept of the multilinguistic conductor.

\section{References}

1 Carbonaro M, King S, Taylor E, Satzinger F, Snart F, Drummond J. Integration of e-learning technologies in an interprofessional health science course. Med Teach 2008;30(01):25-33

2 D'Amour D, Oandasan I. Interprofessionality as the field of interprofessional practice and interprofessional education: an emerging concept. J Interprof Care 2005;19(Suppl 1):8-20

3 Zwarenstein M, Goldman J, Reeves S Interprofessional collaboration. Interprofessional collaboration: effects of practice-based interventions on professional practice and healthcare outcomes. Cochrane Database Syst Rev 2009;(03):CD000072

4 Kvarnström S. Difficulties in collaboration: a critical incident study of interprofessional healthcare teamwork. J Interprof Care 2008;22 (02):191-203

5 Xyrichis A, Lowton K. What fosters or prevents interprofessional team working in primary and community care? A literature review. Int J Nurs Stud 2008;45(01):140-153

6 Atwal A, Caldwell K. Do multidisciplinary integrated care pathways improve interprofessional collaboration? Scand J Caring Sci 2002;16(04):360-367

7 Interprofessional Education Collaborative. Core Competencies for Interprofessional Collaborative Practice: 2016 Update. Washington, DC: Interprofessional Education Collaborative; 2016

8 Morgan MB, Meenan CD, Safdar NM, Nagy P, Flanders AE. Informatics leaders in radiology: who they are and why you need them. J Am Coll Radiol 2014;11(12 Pt B):1241-1250

9 Mitchell R, Parker V, Giles M, White N. Review: toward realizing the potential of diversity in composition of interprofessional health care teams: an examination of the cognitive and psychosocial dynamics of interprofessional collaboration. Med Care Res Rev 2010;67(01):3-26

10 Deeter-Schmelz DR, Norman Kennedy K. Patient care teams and customer satisfaction: the role of team cohesion. J Serv Mark 2003;17(07):666-684

11 Sorbero ME, Farley DO, Mattke S, Lovejoy SL. Outcome Measures for Effective Teamwork in Inpatient Care: Final Report. Santa Monica, CA: Rand Corporation, Health R; 2008:0833046020

12 Lapkin S, Levett-Jones T, Gilligan C. A systematic review of the effectiveness of interprofessional education in health professional programs. Nurse Educ Today 2013;33(02):90-102

13 Baggs JG, Ryan SA, Phelps CE, Richeson JF, Johnson JE. The association between interdisciplinary collaboration and patient outcomes in a medical intensive care unit. Heart Lung 1992;21 (01):18-24

14 Clarke DJ. Achieving teamwork in stroke units: the contribution of opportunistic dialogue. J Interprof Care 2010;24(03): 285-297

15 Thistlethwaite J, Moran M; World Health Organization Study Group on Interprofessional Education and Collaborative Practice. Learning outcomes for interprofessional education (IPE): literature review and synthesis. J Interprof Care 2010;24(05): 503-513

16 Gilbert JH, Yan J, Hoffman SJ. A WHO report: framework for action on interprofessional education and collaborative practice. J Allied Health 2010;39(03, Suppl 1):196-197

17 Institute of Medicine (IOM). Retooling for an Aging America: Building the Health Care Workforce. Washington, DC: National Academies Press; 2008

18 Batalden P, Leach D, Swing S, Dreyfus H, Dreyfus S. General competencies and accreditation in graduate medical education. Health Aff (Millwood) 2002;21(05):103-111

19 Brandt BF, Cerra FB, Delaney CW. The United States National Center for Interprofessional Practice and Education: integrating an informatics approach to interprofessional work. J Interprof Care 2015;29(06):592-595

20 Bennett LM, Gadlin H, Levine-Finley S. Collaboration \& Team Science: A Field Guide. NIH Office of the Ombudsman, Center for Cooperative Resolution. Bethesda, MD: National Institutes of Health; 2010

21 Mitchell D, Haroun L. Introduction to Health Care. Clifton Park, NY: Delmar Cengage Learning; 2017. Available at: https://www. r2library.com/Resource/Title/130557477X

22 Schultz JS, Götz K. Collaborative decision-making. In: Salloch S, Sandow V, Schildmann J, Vollmann J, eds. Ethics and Professionalism in Healthcare: Transition and Challenges. 1st ed. Abingdon, Oxon, and New York, NY: Routledge Taylor \& Francis Group; 2016: 39-51 
23 Reeves S, Pelone F, Harrison R, Goldman J, Zwarenstein M. Interprofessional collaboration to improve professional practice and healthcare outcomes. Cochrane Database Syst Rev 2017;6(06): CD000072

24 Lingard L, Vanstone M, Durrant M, et al. Conflicting messages: examining the dynamics of leadership on interprofessional teams. Acad Med 2012;87(12):1762-1767

25 Olson R, Bialocerkowski A. Interprofessional education in allied health: a systematic review. Med Educ 2014;48(03):236-246

26 Chamberlain-Salaun J, Mills J, Usher K. Terminology used to describe health care teams: an integrative review of the literature. J Multidiscip Healthc 2013;6:65-74

27 Gassert CA, Peay WJ, Mitchell JA. A model of interprofessional informatics education. Stud Health Technol Inform 2006; 122:149-152

28 Detmer DE. Interprofessional clinical informatics education and practice: essentials for learning healthcare systems worldwide. J Interprof Care 2017;31(02):187-189

29 Mitchell P, Wynia M, Golden R, et al. Core Principles \& Values of Effective Team-Based Health Care. Washington, DC: Institute of Medicine; 2012

30 ChristophersonTA, Troseth MR, Clingerman EM. Informatics-enabled interprofessional education and collaborative practice: a frameworkdriven approach. J Interprof Educ Pract. 2015;1(01):10-15

31 Cimino JJ, Shortliffe EH. Biomedical Informatics: Computer Applications in Health Care and Biomedicine. 4th ed. London: Springer; 2014

32 Bloomrosen M, Detmer DE. Informatics, evidence-based care, and research; implications for national policy: a report of an American Medical Informatics Association health policy conference. J Am Med Inform Assoc 2010;17(02):115-123

33 Williams MS, Ritchie MD, Payne PRO. Interdisciplinary training to build an informatics workforce for precision medicine. Appl Transl Genomics 2015;6:28-30

34 Lobach DF, Kawamoto K, Anstrom KJ, et al. Proactive population health management in the context of a regional health information exchange using standards-based decision support. AMIA Annu Symp Proc 2007; ::473-477

35 Savel TG, Foldy S; Centers for Disease Control and Prevention. The role of public health informatics in enhancing public health surveillance. MMWR Suppl 2012;61(03):20-24

36 Krumholz HM. Big data and new knowledge in medicine: the thinking, training, and tools needed for a learning health system. Health Aff (Millwood) 2014;33(07):1163-1170

37 Friedman C, Rubin J, Brown J, et al. Toward a science of learning systems: a research agenda for the high-functioning Learning Health System. J Am Med Inform Assoc 2015;22(01):43-50

38 Herland M, Khoshgoftaar TM, Wald R. A review of data mining using big data in health informatics. J Big Data. 2014;1(01):2

39 U.S. National Library of Medicine. Health Informatics; September 2017. Available at: https://www.nlm.nih.gov/hsrinfo/informatics. html. Accessed September 2, 2017

40 Kuziemsky C, Reeves S. The intersection of informatics and interprofessional collaboration. J Interprof Care 2012;26(06): 437-439

41 AMIA Accreditation Committee. [No title]. 2017. Available at: https://www.cahiim.org/documents/FINAL AMIA Health Informatics Core Competencies for CAHIIM.pdf. Accessed January 1, 2018

42 Gardner RM, Overhage JM, Steen EB, et al; AMIA Board of Directors. Core content for the subspecialty of clinical informatics. J Am Med Inform Assoc 2009;16(02):153-157

43 Schleyer T, Moore HE, Weaver K. Effective interdisciplinary teams. In: Finnell JT, Dixon BE, eds. Clinical Informatics Study Guide: Text and Review. 1st ed. Zurich: Springer International Publishing; 2016:343-376

44 Finnell JT, Dixon BE. Clinical Informatics Study Guide: Text and Review. 1st ed. Zurich: Springer International Publishing; 2015
45 Nancarrow SA, Booth A, Ariss S, Smith T, Enderby P, Roots A. Ten principles of good interdisciplinary team work. Hum Resour Health 2013;11:19

46 Hall P. Interprofessional teamwork: professional cultures as barriers. J Interprof Care 2005;19(01, Suppl 1):188-196

47 Thibault GE. Reforming health professions education will require culture change and closer ties between classroom and practice. Health Aff (Millwood) 2013;32(11):1928-1932

48 Salas E, DiazGranados D, Weaver SJ, King H. Does team training work? Principles for health care. Acad Emerg Med 2008;15(11): 1002-1009

49 Macdonald MB, Bally JM, Ferguson LM, Lee Murray B, FowlerKerry SE, Anonson JM. Knowledge of the professional role of others: a key interprofessional competency. Nurse Educ Pract 2010;10(04):238-242

50 Agency for Healthcare Research and Quality. Pocket Guide: TeamSTEPPS. Team Strategies \& Tools to Enhance Performance and Patient Safety. Rockville, MD: Agency for Healthcare Research and Quality [updated January 2014]. Available at: https://www.ahrq.gov/teamstepps/instructor/essentials/pocketguide.html. Accessed September 2,2017

51 Salas E, Burke CS, Cannon-Bowers JA. Teamwork: emerging principles. Int J Manag Rev 2000;2(04):339-356

52 Salas E, Sims DE, Burke CS. Is there a "big five" in teamwork? Small Group Res 2005;36(05):555-599

53 De Souza G, Klein HJ. Emergent leadership in the group goalsetting process. Small Group Res 1995;26(04):475-496

54 Piwowar HA, Becich MJ, Bilofsky H, Crowley RS; caBIG Data Sharing and Intellectual Capital Workspace. Towards a data sharing culture: recommendations for leadership from academic health centers. PLoS Med 2008;5(09):e183

55 CFAR, Inc., Tomasik J, Fleming C. Lessons from the Field: Promising Interprofessional Collaboration Practices. Princeton, NJ: Robert Wood Johnson Foundation (RWJF); 2015

56 Boaro N, Fancott C, Baker R, Velji K, Andreoli A. Using SBAR to improve communication in interprofessional rehabilitation teams. J Interprof Care 2010;24(01):111-114

57 Caroselli M. Meetings that Work. Revised ed. Mission, KS: Skillpath Publications; 1995

58 Safran C, Bloomrosen M, Hammond WE, et al; Expert Panel. Toward a national framework for the secondary use of health data: an American Medical Informatics Association White Paper. J Am Med Inform Assoc 2007;14(01):1-9

59 Sargeant J, Loney E, Murphy G. Effective interprofessional teams: "contact is not enough" to build a team. J Contin Educ Health Prof 2008;28(04):228-234

60 Masters C, Baker VOT, Jodon H. Multidisciplinary, team-based learning: the simulated interdisciplinary to multidisciplinary progressive-level education (SIMPLE@) approach. Clin Simul Nurs 2013;9(05):e171-e178

61 Bridges DR, Davidson RA, Odegard PS, Maki IV, Tomkowiak J. Interprofessional collaboration. Interprofessional collaboration: three best practice models of interprofessional education. Med Educ Online 2011;16:16

62 Melton GB, Parsons S, Morrison FP, Rothschild AS, Markatou M, Hripcsak G. Inter-patient distance metrics using SNOMED CT defining relationships. J Biomed Inform 2006;39(06):697-705

63 Mickan S, Rodger S. Characteristics of effective teams: a literature review. Aust Health Rev 2000;23(03):201-208

64 Cannon-Bowers JA, Tannenbaum SI, Salas E, Volpe CE. Defining competencies and establishing team training requirements. In: Guzzo RA, Salas E, eds. Team Effectiveness and Decision Making in Organizations. San Francisco: Jossey Bass; 1995: 333-380

65 Zaccaro SJ, Rittman AL, Marks MA. Team leadership. Leadersh Q 2001;12(04):451-483

66 Day DV, Gronn P, Salas E. Leadership capacity in teams. Leadersh Q 2004;15(06):857-880 
148 Best Practices for Health Informatician Involvement Holden et al.

67 Dinh JE, Lord RG, Gardner WL, Meuser JD, Liden RC, Hu J. Leadership theory and research in the new millennium: current theoretical trends and changing perspectives. Leadersh Q 2014;25 (01):36-62

68 Nelson R, Staggers N. Foundational information in health informatics. In: Nelson R, Staggers N, eds. Health Informatics: An Interprofessional Approach. 2nd ed. St. Louis, MO: Elsevier; 2016: $1-75$

69 Maojo V, Kulikowski CA. Note on Friedman's 'what informatics is and isn't'. J Am Med Inform Assoc 2013;20(e2):e365-e366

70 Kulikowski CA, Shortliffe EH, Currie LM, et al. AMIA Board white paper: definition of biomedical informatics and specification of core competencies for graduate education in the discipline. J Am Med Inform Assoc 2012;19(06):931938

71 van Mulligen EM, Cases M, Hettne $\mathrm{K}$, et al. Training multidisciplinary biomedical informatics students: three years of experience. J Am Med Inform Assoc 2008;15(02):246-254

72 Friedman CP. What informatics is and isn't. J Am Med Inform Assoc 2013;20(02):224-226

73 Gadd CS, Williamson JJ, Steen EB, Fridsma DB. Creating advanced health informatics certification. J Am Med Inform Assoc 2016;23 (04):848-850

74 Khairat S, Sandefer R, Marc D, Pyles L. A review of biomedical and health informatics education: a workforce training framework. J Hosp Adm 2016;5(05):10-20 